\title{
Cloning, expression and purification of outer membrane protein PorA of Neisseria meningitidis serogroup B
}

\author{
Fakhri Haghi ${ }^{1}$, Shahin Najar Peerayeh ${ }^{1}$, Seyed Davar Siadat ${ }^{2}$, Mehran Montajabiniat $^{1}$ \\ ${ }^{1}$ Department of Bacteriology, Faculty of Medical Sciences, Tarbiat Modares University, Tehran, Iran \\ ${ }^{2}$ Department of Hepatitis and AIDS, Pasteur Institute of Iran, Tehran, Iran
}

\begin{abstract}
Introduction: Neisseria meningitidis is a major causative agent of bacterial septicemia and meningitis in humans. Currently, there are no vaccines to prevent disease caused by strains of $N$. meningitidis serogroup B. PorA is a major component of the outer membrane of $N$. meningitidis and functions as a cationic porin. This study aimed to clone and determine the expression of PorA.

Methodology: A 1200 bp fragment of porA gene was amplified by PCR from serogroup B N. meningitidis and then cloned into prokaryotic expression vector pET-32a. For expression of recombinant protein, pET32a-porA plasmid was transformed into competent Origami B (DE3) cells. Recombinant protein was overexpressed with isopropythio-beta-D-galctoside (IPTG) and affinity purified by Ni-NTA agarose. SDSPAGE and western blotting were performed for protein determination and verification.

Results: Cloning of porA was confirmed by colony-PCR and enzymatic digestion. In comparison with the corresponding sequences of original genes, the nucleotide sequence homology of the cloned porA gene was $97 \%$. IPTG with a dosage of $1.0 \mathrm{mmol} / \mathrm{L}$ could efficiently induce protein expression. SDS-PAGE analysis showed that our constructed prokaryotic expression system pET32a-PorA-Origami efficiently produces a target recombinant protein with a molecular weight of $65 \mathrm{kDa}$. The recombinant PorA was overexpressed as inclusion bodies and reacted with the serum from a rabbit previously immunized with native outer membrane vesicle.

Conclusion: This prokaryotic expression system provides an easy method for producing recombinant PorA and may also be useful for the production of other bacterial outer membrane proteins for vaccine studies.
\end{abstract}

Key words: Neisseria meningitidis; PorA; Ni-NTA agarose; pET-32a

J Infect Dev Ctries 2011; 5(12):856-862.

(Received 06 September 2010 - Accepted 06 March 2011)

Copyright (c) 2011 Haghi et al. This is an open-access article distributed under the Creative Commons Attribution License, which permits unrestricted use, distribution, and reproduction in any medium, provided the original work is properly cited.

\section{Introduction}

Neisseria meningitidis is an encapsulated, Gramnegative diplococcus that causes bacterial meningitis and septicemia; therefore, it is considered a major public health problem [1]. Meningococcal strains are classified into 13 serogroups based on the chemical composition of the polysaccharide capsule [2]. Serogroups A, B, C, Y, and $\mathrm{W}-135$ are associated with disease worldwide [3]. Antibiotic therapy is often ineffective to treat meningococcal infections and vaccination is considered an attractive approach for prophylactic purposes [4].

Polysaccharide conjugate vaccines are available for N. meningitidis serogroups A, C, Y and W135 [5]. However, due to the structural similarity of the $\mathrm{N}$ acetylneuraminic acid component of the serogroup B capsular polysaccharide with surface glycoproteins of human fetal cells, there is no similar vaccine for serogroup B [6]. Alternative antigens are being evaluated as candidates for vaccine [7]. Non capsular candidate vaccines based on outer membrane vesicles
(OMVs) and outer membrane proteins (OMPs) such as PorA, PorB, NadA, NhhA, and AppA have been designed previously [8]. PorA (class 1 OMP) is a major protein of $44 \mathrm{kDa}$ that is encoded by the porA gene locus and forms trimeric cationic pores in the outer membrane [9]. This transmembrane protein consists of a 16-strand beta-barrel, eight of which are surface exposed loops. Two of these extracellular loops (loops 1 and 4) are highly immunogenic and evoke bactericidal antibodies [10]. PorA has been shown to induce bactericidal immune responses in human serum following natural disease and immunization [11]. In humans, the protein elicits a more protective immune response than any other meningococcal surface protein [12]. Much of this evidence comes from the clinical evaluation of OMV vaccines in which PorA is the immunodominant antigen [13]. Recombinant OMV-formulations with various PorA antigens have been developed in some countries; therefore, it can be considered a reliable candidate antigen as a part of a multi-component 
recombinant protein vaccine [14]. The aim of the present study was to construct a prokaryotic highlevel expression system for producing recombinant outer membrane protein PorA which can be used for vaccine development in the future.

\section{Methodology}

Bacterial strains and vector

$N$. meningitidis CSBPI, G-245 was kindly obtained from the Pasteur Institute of Iran and was grown on chocolate agar. Escherichia coli strains DH5 $\alpha$ (Invitrogen, California, USA) and Origami B (DE3) (Novagen, Wisconsin, USA) were used for cloning and expression of the recombinant protein, respectively. The $E$. coli cells harboring recombinant plasmids were grown aerobically at $37^{\circ} \mathrm{C}$ in LuriaBertani (Merck, Darmstadt, Germany) broth with or without $50 \mu \mathrm{g} / \mathrm{ml}$ Ampicillin (Sigma, Saint Louis, MO, USA). Plasmid pET-32a (Novagen, Wisconsin, USA) was used as an expression vector.

\section{Amplification of porA}

Genomic DNA from serogroup B $N$. meningitidis CSBPI, G-245 was extracted using the phenolchloroform method and dissolved in TE buffer [15]. The full coding sequence of porA (1200 bp) was amplified by polymerase chain reaction (PCR) using specific primers. To ensure correct orientation into the multiple cloning sites of the vector, the forward primer

GACGGATCCATGCGAAAAAAACTTACC-3') incorporated a BamHI restriction enzyme site, whereas the reverse primer (5ATACTCGAGTTAGAATTTGTGGCGCAAACC-

3') incorporated an XhoI site. Amplification of the DNA was achieved by using Prime STAR DNA polymerase (Takara, Osaka, Japan); a $25-\mu 1$ reaction mixture contained 0.5 pmol of each primer, $5 \mu 15 \mathrm{X}$ prime STAR buffer, $0.2 \mathrm{mM}$ concentration of each dNTP, $2.5 \mathrm{U}$ of prime STAR DNA polymerase, and $100 \mathrm{ng}$ genomic DNA. Amplification was performed by using 30 cycles of denaturation at $94^{\circ} \mathrm{C}$ for 10 seconds, annealing at $57.5{ }^{\circ} \mathrm{C}$ for 15 seconds, extension at $72^{\circ} \mathrm{C}$ for 90 seconds and 10 minutes at $72^{\circ} \mathrm{C}$ for the final extension. The PCR products were recovered from the gel and purified by using the PCR purification kit (Bioneer, Taejon, South Korea).

\section{Cloning and expression of porA}

The purified porA fragment was digested with the restriction enzymes $\mathrm{BamHI}$ and $\mathrm{XhoI}$ and ligated into the BamHI-XhoI sites of pET32a vector, which provides six His residues at the $\mathrm{N}$-terminus of the expressed protein. Recombinant vector pET32a-porA was transformed into competent $E$. coli $\mathrm{DH} 5 \alpha$ cells. The integrity of the recovered plasmid was confirmed by restriction endonuclease digestion and sequencing of the porA insert by a commercial facility using universal T7-promoter and T7-terminator primers (TAG Copenhage A/S Symbion, Denmark).

For expression of the recombinant protein, pET32a-porA plasmid was transformed into competent Origami B (DE3) cells. Origami cells harboring a pET-32a-porA vector were grown in LB medium supplemented with Ampicillin $(50 \mu \mathrm{g} / \mathrm{ml})$ at $37^{\circ} \mathrm{C}$ with shaking $(250 \mathrm{rpm})$ to $A_{650}$ of 0.7 ; then isopropyl- $\beta$-D-thiogalactopyranoside (IPTG) was added to a final concentration of $1 \mathrm{mmol} / \mathrm{L}$. The cells were incubated for a further 4 hours before being harvested.

\section{Purification of recombinant PorA}

A pellet of Origami cells harboring rPorA was suspended by gentle stirring in lysis buffer $(1 \%$ Triton X100, 20mM Tris-HCl, 10mM EDTA, pH 7.5). The suspension was subjected to sonication (five cycles, 1 minute each, with intervals of 1 minute on ice) and then centrifuged for 20 minutes at $6000 \times$ g. After centrifugation, the supernatant and precipitate were examined by sodium dodecyl sulfate polyacrylamide gel electrophoresis (SDS-PAGE) to verify the location of the expressed recombinant protein. The crude rPorA was purified by affinity chromatography on a nickel-nitrilotriacetic acid (NiNTA) gel matrix (Qiagen, Crawley, United Kingdom) under denaturing conditions. A column containing $5 \mathrm{ml}$ of Ni-NTA resin was equilibrated with 10 volumes of buffer containing $8 \mathrm{M}$ urea, 0.1 $\mathrm{M} \mathrm{NaH} \mathrm{PO}_{4}$, and $0.01 \mathrm{M}$ Tris ( $\mathrm{pH}$ 8.0), and the cleared cell lysate was loaded onto the column. The column was washed with 5 volumes of wash buffer (8 M urea, $0.1 \mathrm{M} \mathrm{NaH}_{2} \mathrm{PO}_{4}, 0.01 \mathrm{M}$ Tris ( $\mathrm{pH} 8.0$ ) and $20 \mathrm{mM}$ imidazole), followed by 5 volumes of the same buffer, but at $\mathrm{pH}$ 6.3. The $\mathrm{rPilQ}_{406-770}$ protein was then eluted by increasing the imidazole concentration to $250 \mathrm{mM}$. Fractions containing the recombinant protein were pooled and dialyzed against PBS, pH 7.4 to remove imidazole. Protein concentrations were determined by Nanodrop analyzer (Bio-Rad, Hercules, CA, USA) and the purity was determined by SDS-PAGE and Coomassie blue staining. 
Figure 1. Electrophoresis of outer membrane protein PorA PCR product on agarose gel $(1 \% \mathrm{w} / \mathrm{v})$. Lane 1: $1 \mathrm{~kb}$ DNA size marker, Lane 2, 3: Single expected band of porA gene (1200 bp)

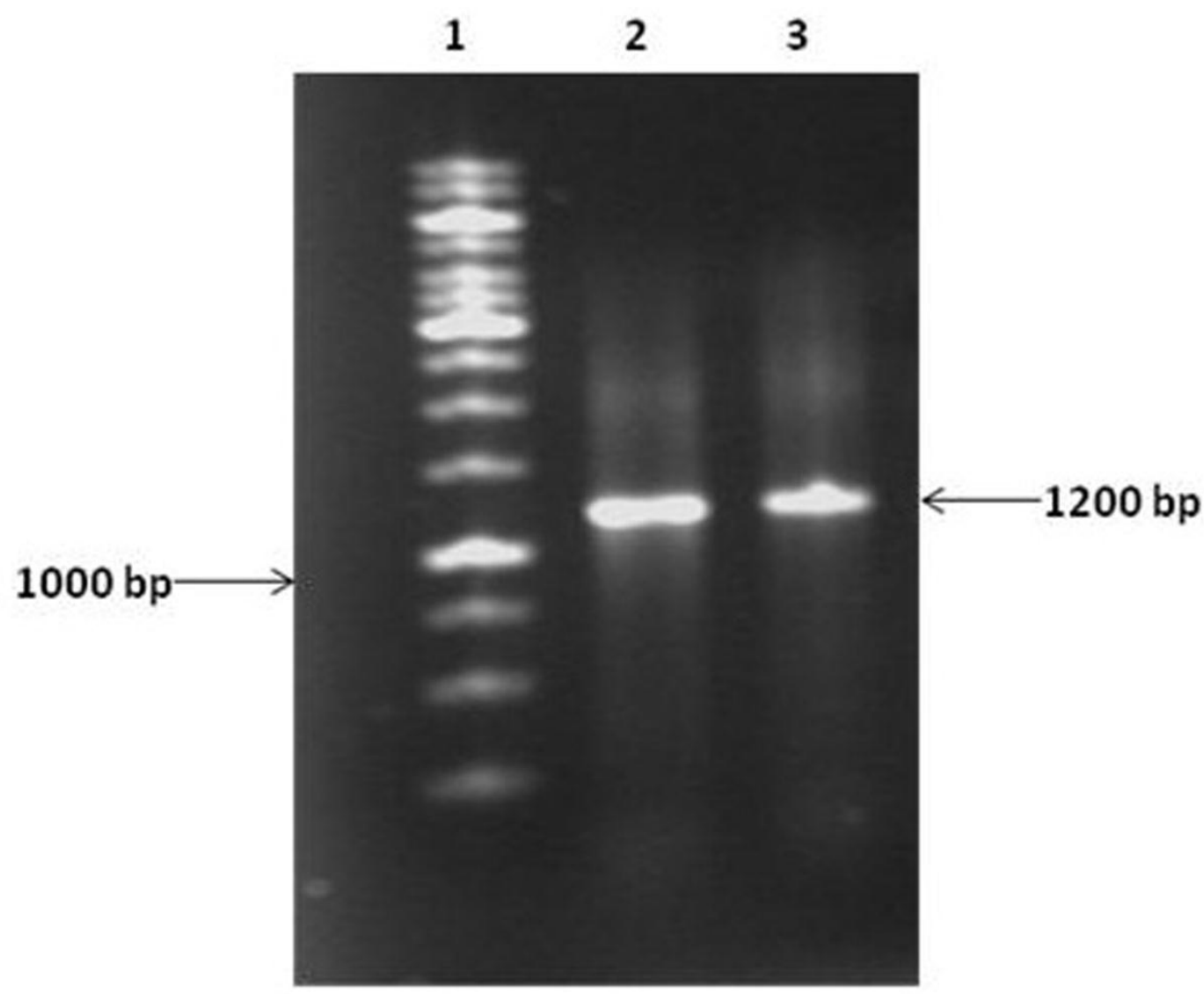

Anti OMV-PorA antibody production

Female New Zealand white rabbits (Pasteur research institute, Tehran, Iran) were immunized subcutaneously with $100 \mu \mathrm{g}$ of native meningococcal OMV-PorA obtained by sodium deoxycholate extraction in complete Freund's adjuvant (Sigma, Saint Louis, MO, USA). Booster doses were also given in incomplete Freund's adjuvant at two and 4 foureeks. Ten days after the last immunization, the animals were exsanguinated by cardiac puncture under anesthesia and serum samples were collected and stored at $-20^{\circ} \mathrm{C}$ until required for use. All animal experiments were done in accordance with institutional and national ethical guidelines.

\section{Western blot analysis}

The separated proteins by SDS-PAGE were blotted onto a $0.45 \mu \mathrm{m}$ pore size polyvinylidene difluoride (PVDF) membrane (Hi-bond Amersham Biosciences, USA) by using a semi-dry blotter unit (Labconco, Kansas City, Mo). The membrane was blocked by $1 \%$ skim milk and then the PVDF membrane was incubated with native immune serum (diluted to 1:1000 in PBS-Tween 20) for 2 hours at room temperature. The membrane was washed with PBS-Tween 20 and then incubated with sheep antirabbit immunoglobulin G (heavy and light chain) horseradish peroxidase (HRP) conjugate antibody (diluted to 1:3000 in PBS-Tween 20) for one hour at room temperature. After washing three times, the membrane was treated using DAB solution (Sigma, Saint Louis, MO, USA) and placed in darkness to develop the protein band.

\section{Results}

Amplification of porA and construction of pET32aporA

Specific primers were designed to amplify porA from the $N$. meningitidis CSBPI, G245. The expected size of the porA PCR product, approximately 1200 $\mathrm{bp}$, is shown in Figure 1. The integrity of the recombinant vector pET32a-porA was confirmed by double digestion using $\mathrm{BamHI}$ and $\mathrm{XhoI}$ restriction 
Figure 2. Electrophoresis of recombinant pET32a-porA on agarose gel (1\% w/v). Lane 1: 1 $\mathrm{kb}$ DNA size marker, lane2: Double digestion of recombinant pET-32a-porA with BamHI and XhoI restriction enzymes (pET32a: 5900bp and porA: 1200bp)

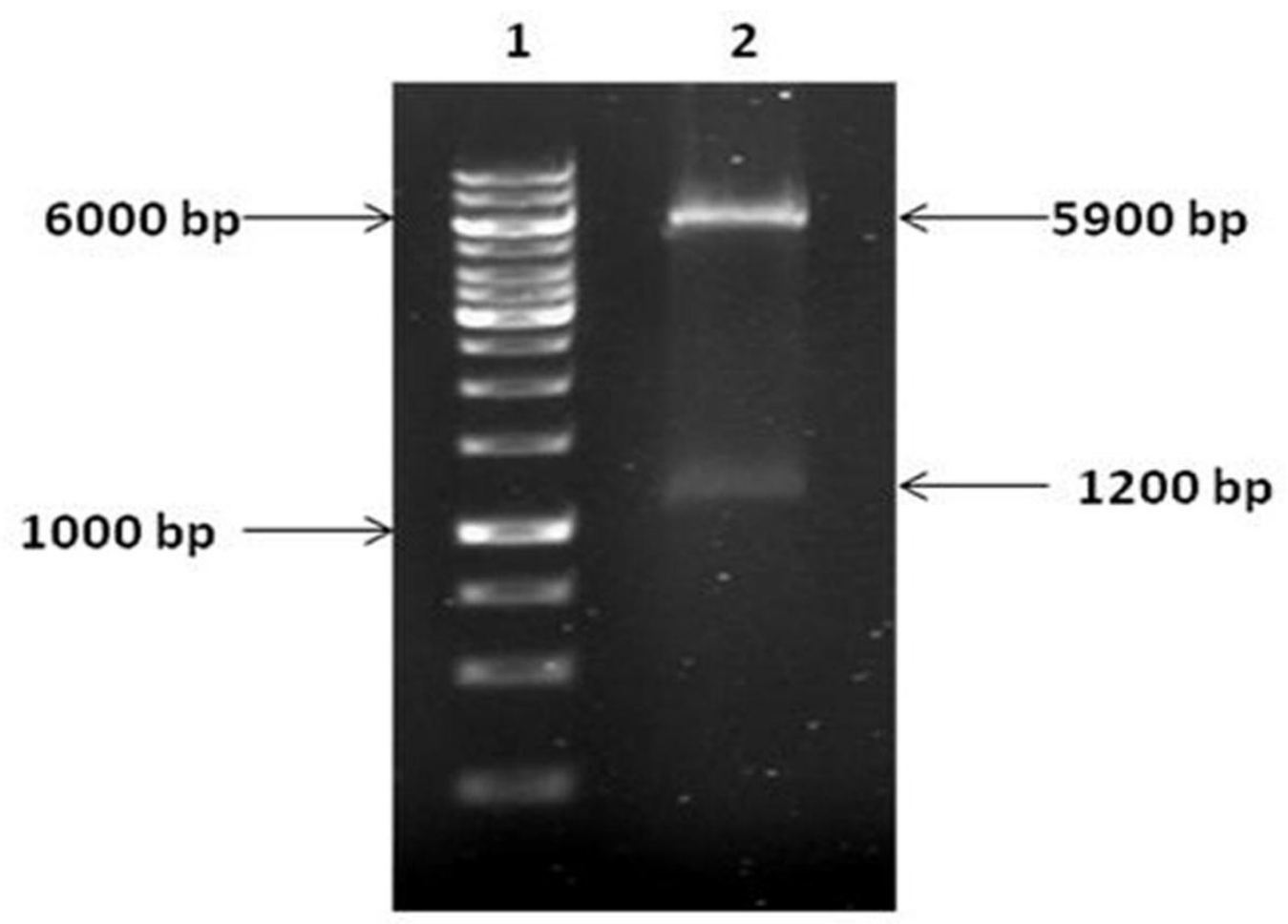

Figure 3. SDS-PAGE analysis of recombinant PorA with Coomassie-stained. Expression of PorA in Origami cells induced with $1.0 \mathrm{mmol} / \mathrm{L}$ IPTG. Lane 1: Protein marker, Lane 2, 3: Non-induced with IPTG, lane 4, 5: Induced with IPTG (65 kDa)

1

2

3

45

116 kDa

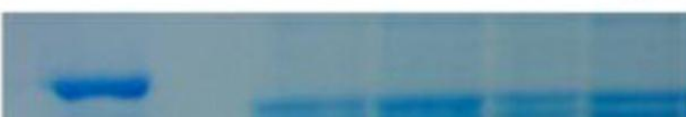

$66 \mathrm{kDa}$

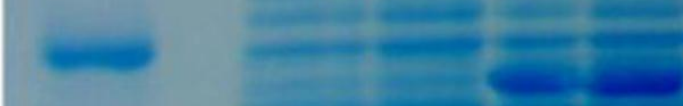

$\longleftarrow-65 \mathrm{kDa}$

$45 \mathrm{kDa}$

35 kDa

$25 \mathrm{kDa}$ 
Figure 4. SDS-PAGE analysis of purified recombinant PorA with Coomassie-stained. Lane1: protein marker, lane 2: recombinant PorA with molecular weight of $65 \mathrm{kDa}$ that purified with Ni-NTA affinity chromatography

12

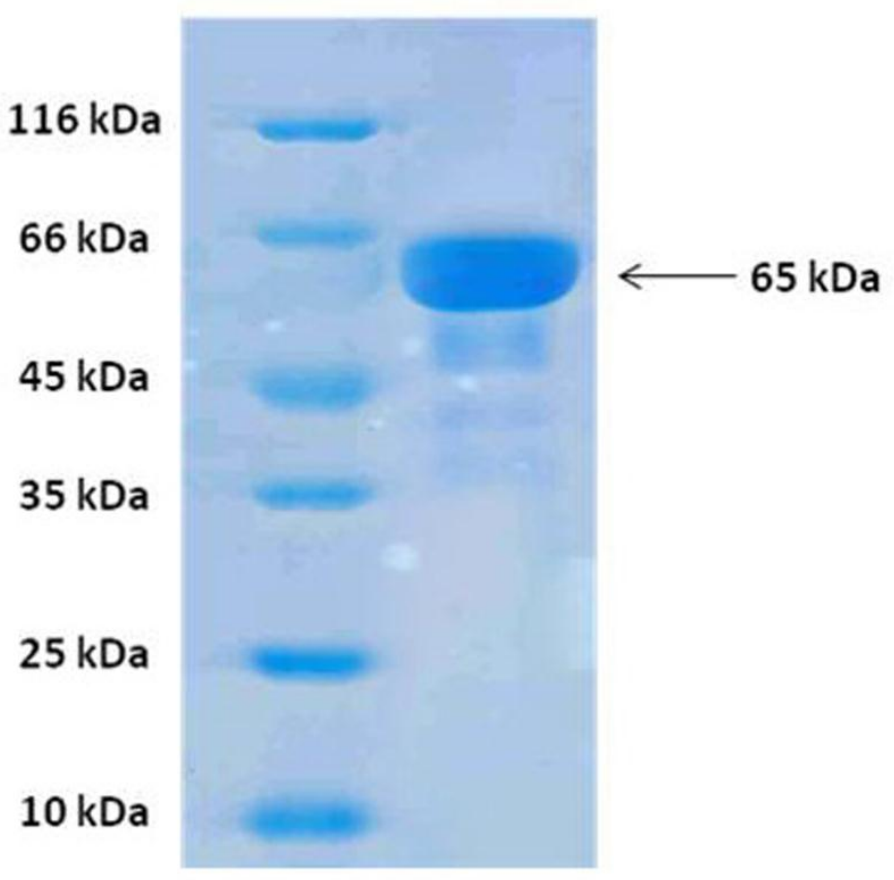

enzymes (Figure 2) and colony-PCR with specific primers. Identity and orientation of porA in the construct was confirmed by sequencing the recombinant vector. Cloned porA gene sequence showed $97 \%$ homology with the reference sequences.

\section{Expression and purification of PorA}

Origami cells harboring pET32a-porA plasmid were cultured at $37^{\circ} \mathrm{C}$ in the presence and absence of an inducer IPTG. The whole-cell lysates were analyzed by $12 \%$ SDS-PAGE. One major band appeared approximately at the $65 \mathrm{kDa}$ position after IPTG induction, which was the expected position of PorA (Figure 3). Induction of the cells with IPTG $(1.0 \mathrm{mmol} / \mathrm{L})$ at $37^{\circ} \mathrm{C}$ for 4 hours was found to be optimal to achieve high-level expression of PorA. Both supernatant and the pellet of cell lysates were tested for the presence of recombinant proteins and the majority of the expressed protein was detected in inclusion bodies. Recombinant protein was carefully purified with Ni-NTA affinity chromatography under denaturing conditions (Figure 4). The output of rPorA was approximately $50 \%$ of the total bacterial proteins and the highest detectable level of purified rPorA was up to $0.4 \mathrm{mg} / \mathrm{ml}$.

\section{Western blot analysis}

Western blot analysis was performed to detect the antigenicity of the expressed protein. The $65 \mathrm{kDa}$ protein band, observed in SDS-PAGE, was confirmed as PorA protein by western blot analysis using with rabbit anti-OMV antibodies.

\section{Discussion}

The outer membrane proteins in Gram-negative bacteria have particular significance as a potential target for protective immunity [16]. Class 1 outer membrane protein (PorA) is a major component of the outer membrane of Neisseria meningitidis and functions as a cationic porin [17]. Previous studies have shown that PorA is immunogenic during natural infection and is also a target for bactericidal antibodies, following immunization with experimental OMVs $[18,19]$. In clinical vaccination trials with OMVs, it has been shown that PorA is critical for the induction of bactericidal antibodies in humans [10]. Arigita et al. showed that purified recombinant PorA was immunogenic in the mouse model [20]. 
The main difficulty with PorA antigens is that they are antigenically diverse and display considerable temporal and geographical variability [21]. A single PorA vaccine component would achieve limited coverage among more heterogeneous populations. To provide protection against heterologous strains, recombinant multivalent OMV vaccines consisting of various PorA antigens (hexavalent and nanovalent) have been developed in the Netherlands [22]. Recent reports on serogroup B meningococcal vaccine candidates have focused on complex mixtures of conserved proteins such as fHbp, NadA, and NHBA [23,24,12].

Traditionally, preparation of native PorA for immunological and in vitro studies is time-consuming and needs large volumes of bacterial culture, sophisticated technical equipment and the performance of several purification steps that usually lead to a low yield [25]. Therefore, developing a method to overcome to conventional approaches is an asset. In the present study, recombinant DNA technology was applied to obtain PorA. Among the available protein expression systems, $E$. coli is most commonly used because of its well-characterized genetics, rapid growth characteristics, ability to utilize inexpensive substrates, and the availability of an increasingly large number of cloning vectors and mutant host strains [26,27].

PorA has previously been expressed as a fusion protein in Bacillus subtilis and E. coli strain E2566 [19]. In this study, we report the cloning of porA in a pET-32a vector and its expression in Origami. We believe that this is the first report of overexpression of recombinant PorA with a His-tag in Origami cells. pET-32a vector carries six histidine residues in the Nterminal of the fusion protein. The His tag facilitates purification of the recombinant protein by $\mathrm{Ni}^{+2}$ Sepharose resin. Highly purified recombinant protein was obtained after purification. The output of rPorA was approximately $50 \%$ of the total bacterial proteins that might be beneficial to industrial production. Our efforts at refolding the solubilized proteins using dialysis led to the precipitation and aggregation of many proteins. In contrast, the on-column purification and refolding approach effectively refolded the desired recombinant protein without protein aggregation or precipitation. In Western blotting, the reaction of rabbit anti native serum with recombinant PorA demonstrates the presence of common epitopes between native and recombinant proteins. One of the limitations of our study was that we did not have recombinant commercial protein as a control or monoclonal antisera to verify our findings.

In summary, the pET32a-porA-Origami system has been used to express a recombinant outermembrane protein from $N$. meningitidis to study its potential as a vaccine antigen and may provide an easy method for producing other bacterial outer membrane proteins for the same purpose.

\section{References}

1. Vermont CL, van Dijken HH, Kuipers AJ, van Limpt CJP, Keijzers WCM, van der Ende A, de Groot R, van Alphen L, van den Dobbelsteen GP (2003) Cross-reactivity of antibodies against PorA after vaccination with a meningococcal B outer membrane vesicle vaccine. Infect Immun 71: 1650-1655.

2. Comanducci M, Bambini S, Caugant DA, Mora M, Brunelli B, Capecchi B, Ciucchi L, Rappuoli R, Pizza M (2004) NadA diversity and carriage in Neisseria meningitides. Infect Immun 72: 4217-4223.

3. Beernink PT, Granof DM (2008) Bactericidal antibody responses induced by meningococcal recombinant chimeric factor H-binding protein vaccines. Infect Immun 76: 25682575.

4. Li Y, Sun YH, Ison C, Levine MM, Tang CM (2004) Vaccination with attenuated Neisseria meningitidis strains protects against challenge with live Meningococci. Infect Immun 72: 345-351.

5. Sun Y, Li Y, Exley RM, Winterbotham M, Ison C, Smith H, Tang CM (2005) Identification of novel antigens that protect against systemic meningococcal infection. Vaccine 23: 4136-4141.

6. Humphries H, Williams JN, Christodoulides M, Heckels JE (2004) Recombinant meningococcal PorA protein, expressed usinga vector system with potential for human vaccination, induces a bactericidal immune response. Vaccine 22: 1564-1569.

7. Weynants VE, Feron CM, Goraj KK, Bos MP, Denoel PA, Verlant VG, Tommassen J, Peak I, Judd R, Jennings M, Poolman JT (2007) Additive and synergistic bactericidal activity of antibodies directed against minor outer membrane proteins of Neisseria meningitides. Infect Immun 75: 54345442.

8. Bowe F, Lavelle EDC, McNeela Edel A, Hale C, Clare S, Arico B, Giuliani MM, Rae A, Huett A, Rappuoli R, Dougan G, Mills K (2004) Mucosal vaccination against serogroup B Meningococci: Induction of bactericidal antibodies and cellular immunity following intranasal immunization with NadA of $N$. meningitidis and mutants of E. coli Heat-Labile Enterotoxin. Infect Immun 72: 40524060.

9. Ende A, Hopman CTP, Zaat S (1995) Variable expression of class 1 outer membrane protein in Neisseria meningitidis is caused by variation in the spacing between the -10 and -35 Regions of the Promoter. Infect Immun 177: 2475-2480.

10. van den Elsen J, Vandeputte-Rutten L, Kroon J, Gros P (1999) Bactericidal Antibody Recognition of Meningococcal PorA by Induced Fit comparison of liganded and unliganded fab structures. J Biol Chem 274: 1495-1501.

11. Peeters CCAM, Rumke HC, Sundermann LC, van der Voort EM, Meulenbelt J, Schuller M, Kuipers AJ, van der Ley P, 
Poolman JT (1996) Phase-I clinical-trial with a hexavalent PorA containing meningococcal outer-membrane vesicle vaccine. Vaccine 14: 1009-15.

12. Feaversa IF, Pizza M (2009) Meningococcal protein antigens and vaccines. Vaccine 27: 42-50.

13. van den Dobbelsteen GP, van Dijken HH, Pillai S, van Alphen L (2007) Immunogenicity of a combination vaccine containing pneumococcal conjugates and meningococcal PorA OMVs. Vaccine 25: 2491-2496.

14. Arigita C, Bevaart L, Everse LA, Koning GA, Hennink WE, Crommelin DJ, van de Winkel JGJ, van Vugt MJ, Kersten GFA, Jiskoot W (2003) Liposomal Meningococcal B Vaccination: Role of dendritic cell targeting in the development of a protective immune response. Infect Immun 71: 5210-5218

15. Sambrook J, Russell D (2001) Molecular Cloning: a laboratory manual, 3th edition. New York: Cold Spring Harbor Laboratory Press 2344 p.

16. O'Toole PW, Janzon L, Doig P, Huang J, Kostrzynska M, Trust TJ (1995) The putative neuraminyllactose-binding hemagglutinin HpaA of Helicobacter pylori CCUG 17874 is a lipoprotein. J Bacteriol 177: 6049-57.

17. Massari P, Ram S, Macleod H, Wetzler LM (2003) The role of porins in Neisserial pathogenesis and immunity. Trends Microbiol 11: 87-93.

18. Ende A, Hopman CTP, Dankert J (2000) Multiple mechanisms of phase variation of PorA in Neisseria meningitidis. Infect Immun 68: 6685-90.

19. Humphries HE, Christodoulides M, Heckels JE (2002) Expression of the class 1 outer-membrane protein of Neisseria meningitidis in Escherichia coli and purification using a self-cleavable affinity tag. Protein Expr Purif26: 243-248.

20. Arigita C, Kersten GF, Hazendonk T, Hennink WE, Crommelin DJ, Jiskoot W (2003) Restored functional immunogenicity of purified meningococcal PorA by incorporation into liposomes. Vaccine 21: 950-960.

21. Trotter CL, Ramsay ME (2007) Vaccination against meningococcal disease in Europe: review and recommendations for the use of conjugate vaccines. FEMS Microbiol Rev 31: 101-107.

22. Holst J (2007) Strategies for development of universal vaccines against meningococcal serogroup B disease. Hum Vaccine 3: 290-294.

23. Fletcher LD, Bernfield L, Barniak V, Farley JE, Howell A, Knauf M, Ooi P, Smith RP, Weise P, Wetherell M (2004) Vaccine potential of the Neisseria meningitidis 2086 Lipoprotein. Infect Immun 4: 2088-2100.

24. Lucidarme J, Comanducci M, Findlow M, Gray SJ, Kaczmarski EB, Guiver M, Vallely PJ, Oster P, Pizza M, Bambini S, Muzzi A, Borrow R (2010) Characterization of fHbp, nhba (gna2132), nadA, porA, and sequence type in group B meningococcal case isolates collected in England and Wales during January 2008 and potential coverage of an investigational group B meningococcal vaccine. Clin Vaccine Immunol 6: 919-929.

25. Goudarzi G, Sattari M, Habibi Roudkenar M, MontajabiNiyat M, Zavaran-Hosseini A, Mosavi-Hosseini K (2009) Cloning, expression, purification, and characterization of recombinant flagellin isolated from Pseudomonas aeruginosa. Biotechnol Lett 31:1353-1360.

26. Wright JC, Williams JN, Christodoulides M, Heckels JE (2002) Immunization with the recombinant PorB outer membrane protein induces a bactericidal immune response against Neisseria meningitidis. Infect Immun 8: 4028-4034.

27. Sorensen HP, Mortensen KK (2005) Advanced genetic strategies for recombinant protein expression in Escherichia coli. J Biotechnol 115: 113-128.

\section{Corresponding author}

Shahin Najar Peerayeh (PhD)

Department of Bacteriology

Faculty of Medical Sciences

Tarbiat Modares University

Tehran, Iran

Telephone: +982182883870, Fax: +982182884555

Email: najarp_s@modares.ac.ir

Conflict of interests: No conflict of interests is declared. 